\title{
Usos de vírgula em esquema duplo em textos do último ano do EFIl: evidências de características da fala
}

DOI: http://dx.doi.org/10.21165/el.v49i3.2555

\section{Nayra Cristina Paiva'}

\section{Resumo}

O objetivo deste artigo é identificar e caracterizar os usos e não usos da vírgula em esquema duplo em textos do último ano do Ensino Fundamental brasileiro (EFII), partindo da hipótese de que há relação entre o emprego da vírgula e características da fala. Os aspectos teóricos relacionam-se à multidimensionalidade da pontuação (CHACON, 1998) e à relação fala e escrita (CORRÊA, 2004). O conjunto de 38 textos analisados é pertencente ao Banco de Dados de Produções Escritas do Ensino Fundamental II. Buscamos, a partir da análise, corroborar a concepção da escrita heterogênea e, assim, a noção de escrita como modo de enunciação e também a multidimensionalidade dos sinais de pontuação.

Palavras-chave: escrita; fala; pontuação.

1 Universidade Estadual Paulista "Júlio de Mesquita Filho" (UNESP), São José do Rio Preto, São Paulo, Brasil; nayrapv@hotmail.com; https://orcid.org/0000-0003-3633-3571 


\title{
Uses of the comma in double schemes in texts of the Final Year of Brazilian Junior High School: evidence of speech characteristics
}

\begin{abstract}
The purpose of this article is to identify and characterize the uses and non-uses of commas in double schemes in texts of the Final year of Brazilian Junior High School, assuming the hypotheses that there is a relation between the use of comma and speech characteristics. The theoretical aspects are related to multidimensional punctuation (CHACON, 1998) and the relation between speech and writing (CORREAA, 2004). The set of 38 analyzed texts belongs to the Banco de Dados de Produções Escritas do Ensino Fundamental II. From the analysis, it pursues to corroborate the conception of heterogeneity of writing and, therefore, the notion of writing as an enunciation way and also a multidimensional of the punctuation signals.
\end{abstract}

Keywords: writing; speech; punctuation.

\section{Introdução}

Neste trabalho, nos atemos à descrição linguística de aspectos sintáticos envolvidos no emprego de vírgulas em esquema duplo em textos do último ano do Ensino Fundamental brasileiro (EFII), levando em consideração trabalhos já versados sobre escrita e pontuação e a relação entre fala e escrita (CHACON, 1998; CORRÊA, 2004; ARAÚJO-CHIUCHI, 2012; SONCIN, 2014; SONCIN; RODRIGUES, 2018; CARVALHO, 2019).

Temos por objetivo identificar e caracterizar os usos e não usos de vírgula em esquema duplo em textos do último ano do EFIl desde uma perspectiva descritiva de análise dos dados e partindo da hipótese de que há relação entre o emprego da vírgula e características da fala. Para fins de realização desta análise, foi selecionada uma amostra transversal de 38 textos do Banco de Dados de Escrita do Ensino Fundamental II, que será caracterizada mais adiante.

Este artigo organiza-se da seguinte forma: em primeiro lugar, apresentamos os aportes teóricos utilizados na análise; em segundo lugar, caracterizamos o objeto linguístico de investigação e os procedimentos metodológicos adotados; em terceiro lugar, apresentamos as análises e, por fim, tecemos as considerações finais.

\section{Fundamentação teórica}

Em consonância à Corrêa (2004), assumimos a noção da heterogeneidade da escrita no que tange aos modos de se entender o que são práticas sociais letradas e práticas 
sociais orais. Nessa perspectiva, a escrita é definida a partir do encontro entre o oral/ falado e o letrado/escrito. Dessa forma, desconsideramos a dicotomia entre fala e escrita e, assim, o caráter homogêneo da escrita que se pauta no seu ideal de pureza e que a vê como código. Ademais, no que se refere à heterogeneidade, Corrêa aponta que essa é constitutiva da escrita, ou seja, não é apenas uma característica e também não está ligada à exterioridade, mas sim à interioridade da escrita.

Para reconhecimento da heterogeneidade da escrita, Corrêa aponta três modos: (i) a partir de aspectos da representação gráfıca; (ii) por meio da heterogeneidade da língua e (iii) na circulação dialógica que o escrevente faz ao produzir o texto escrito.

No que se refere à (i), Corrêa afirma que o escrevente oscila entre a representação dos sons e a convenção ortográfica ensinada pela escola. É justamente essa oscilação que mostra a heterogeneidade da escrita em seu aspecto ortográfico. Já com relação à (ii), a partir de sua relação com o tempo, a escrita em quase todos os momentos foi vista como código, ou seja, como uma forma de registrar. Não é de todo errada essa visão de código, uma vez que, enquanto forma de registro, a escrita é um código para preservação de patrimônio cultural como a memória de um povo. Entretanto, é como modo de enunciação que a escrita registra as várias histórias. Na medida em que se admite a escrita como modo de enunciação, reconhece-se sua heterogeneidade, uma vez que o fato de registrar várias histórias traz para esse modo de enunciação a heterogeneidade linguística que está presente, justamente, nas práticas sociais da oralidade e letramento.

Por fım, no tocante à (iii), esse modo está relacionado à abordagem da escrita a partir de uma fixação metodológica de três eixos: (i) eixo da representação que o escrevente faz da gênese da escrita; (ii) o eixo da representação que o escrevente faz do código escrito institucionalizado; e (iii) o eixo da dialogia com o falado/escrito. A circulação do escrevente por esses três eixos está ancorada na: (a) consideração da heterogeneidade como constitutiva da escrita; (b) consideração da relação sujeito/linguagem; (c) consideração do processo de produção do texto escrito e (d) consideração da escrita como modo de enunciação. São esses os três eixos que reconhecem a heterogeneidade da escrita. A circulação do escrevente nos dois primeiros eixos se dá por meio de marcas linguísticas que estão presentes na linguagem como marcas prosódicas, sintáticas, lexicais e como marcas dos recursos argumentativos. Já o terceiro eixo é tido como "o móvel de toda a circulação do escrevente".

Ao assumir essa abordagem, concordamos, então, com a afırmação de Corrêa de haver a necessidade de mudar o modo como se encara a escrita, em específico, como se encara a sua heterogeneidade. Assim, mostra-se relevante, nas palavras do autor, o reconhecimento da heterogeneidade na escrita para o reconhecimento da heterogeneidade da escrita, com isso, nos deparamos com a necessidade de se repensar a escrita e vê-la como modo de enunciação marcado pela diversidade linguístico-histórica dos escreventes. No que se 
refere à relevância da heterogeneidade para esse estudo da pontuação, partilho do que Soncin e Rodrigues (2018, p. 1577) apontam:

[...] Ao contrário, entendemos que todo uso da escrita é realizado por um sujeito inserido em e constituído por linguagem nas diferentes práticas sociais. Desse modo, a escrita carrega em si as relações que esse sujeito estabelece entre os fatos linguísticos e as práticas sociais, ou seja, entre oral/falado e letrado/escrito. Sob essa perspectiva, interpretamos que as vírgulas encontradas nos textos são marcas do processo heterogêneo de constituição da escrita, definidas em função da relação indissociável entre práticas orais/faladas e letradas/escritas que constitui o sujeito que escreve.

Associada à perspectiva de Corrêa (2004), no que se refere aos sinais de pontuação em particular, nos ancoramos à concepção de Chacon (1998, p. 121) de que "os sinais de pontuação delimitam unidades na escrita que se caracterizam pela multidimensionalidade da linguagem". Tal concepção é também abordada e comprovada nos estudos de Soncin e Tenani (2015) que versam sobre relações entre o emprego de vírgula e a prosódia. Além disso, em seu estudo, Chacon (1998, p. 113) enaltece a ideia de que a pontuação atribui à escrita um ritmo próprio e, no que concerne a esse ritmo, o autor afırma "o ritmo da escrita é indiciado pelos sinais de pontuação, na medida em que tais marcas gráfico-visuais podem pôr em realce categorias textuais que, relacionadas, promovem o movimento do texto".

Feitas essas considerações, passamos à apresentação da vírgula em esquema duplo como objeto linguístico de investigação e também dos procedimentos metodológicos que nos permitiram levantar e analisar os dados da vírgula em esquema duplo em textos do último ano do EFII.

\section{A vírgula em esquema duplo como objeto linguístico de investigação}

No que se refere ao objeto desta análise, a vírgula, segundo Dahlet (2006), é o sinal de pontuação mais complexo, pois é o único sinal que funciona tanto em esquema duplo quanto em esquema simples. Por esquema duplo, a autora entende estruturas como a exemplificada em (1), em que duas vírgulas são empregadas; por esquema simples, a autora define empregos como o exemplificado em (2).

(01): Um estudo realizado a pedido do secretário-geral da Organização das nações unidas, Kofi Annan, alerta (Z08_8C_03F_05)

(02): Em primeiro lugar, podemos colocar as atitudes diante dos lixos (Z08_8C_01F_05). 
A vírgula é vista como único sinal capaz de atuar simultaneamente em duas amplitudes e é também o sinal sintático por excelência, ou seja, o mais construtor na sintaxe. Em termos de sua função, a autora afırma que "A vírgula, sem dúvida nenhuma, separa. Porém, sua função não se limita a isso, pois, ao separar segmentos de cadeia escrita, ela ativa outras operações sintáticas, que podem se resumir a isto: adicionar, subtrair, inverter" (DAHLET, 2006, p. 142). A vírgula, em esquema duplo, é definida pela autora a partir do conceito de hierarquização, como exemplificado anteriormente em (1), o que a difere do esquema simples, que se define a partir do conceito de segmentação, como exemplificado anteriormente em (2).

Uma característica importante de vírgulas em esquema duplo, objeto desta pesquisa, é haver duas posições para seu emprego dentro de uma estrutura linguística. Assim, há vírgula tanto na fronteira direita quanto na fronteira esquerda da estrutura mobilizada. No que concerne às estruturas sintáticas, essas são classificadas em dois tipos: (i) deslocamento e (ii) encaixamento de termos e/ou orações subordinadas e/ou coordenadas. As figuras (1) e (2), a seguir, exemplificam, respectivamente, a tipologia (ausência-ausência) em estruturas sintáticas de deslocamento e encaixamento, identificadas nos textos analisados.

Figura 1. Exemplo de uso não-convencional da vírgula em esquema duplo em contexto sintático de deslocamento

Concordo, o caquecimento global í um problem a que

Texto: Z08_8B_04F_05

Figura 2. Exemplo de uso não-convencional da vírgula em esquema duplo em contexto sintático de encaixamento

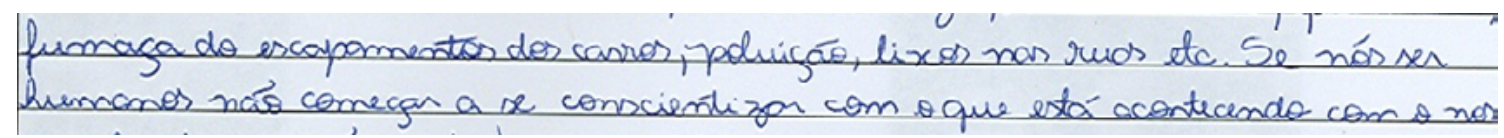

Texto: Z08_8B_34M_02

A Figura 1 exemplifica o uso da vírgula em esquema duplo em contexto sintático de deslocamento, nesse caso, a estrutura sintática deslocada é de adjunto adverbial de tempo "a cada dia". Já a Figura 2 exemplifica esse mesmo uso da vírgula, mas em contexto sintático de encaixamento, nesse caso, um termo "seres humanos" é encaixado entre o sujeito e o verbo da oração principal. 
Neste artigo, o uso da vírgula em esquema duplo será abordado enquanto objeto linguístico de investigação, levando em conta estudos prévios que analisaram sintática e prosodicamente o emprego de vírgulas em textos escritos (ARAÚJO-CHIUCHI, 2012; SONCIN, 2014; CARVALHO, 2019) e que partiram de uma relação não dicotômica entre fala e escrita, ao contrário, de uma noção ampla relacionada à noção de heterogeneidade constitutiva da escrita. Dessa forma, enxergar a escrita sob essa noção de heterogeneidade é enxergá-la como processo, o que interfere no seu ensino e também no modo como se trata a pontuação.

No âmbito do ensino, Carvalho (2019) chama a atenção para o fato de que, segundo a UNESCO, o Brasil ainda enfrenta sérios problemas no que concerne a fornecer qualidade e equidade no ensino, tendo em vista a dificuldade apresentada por uma relevante parcela de alunos na aprendizagem de conteúdos que são previstos em documentos oficiais como a Base Nacional Comum Curricular (2017). No que diz respeito ao ensino de escrita, a vírgula é um tópico, dentre os conteúdos previstos, a ser dominado pelos alunos que chegam ao Ensino Médio, segundo a BNCC (2018). Assume-se que a pontuação que não atende a convenções é parte dos desafios a serem enfrentados juntamente das atividades de leitura e escrita, na linha do que é abordado no documento da UNESCO. Nesse mesmo sentido, "[...] trataremos de um dos principais desafios para o ensino de Língua Portuguesa que é o emprego de vírgula [...]" (CARVALHO, 2019, p. 19) e, em consonância com a autora, buscamos, com a análise desses dados, contribuir para o Ensino da Língua Portuguesa no Brasil, visando o ensino e aprendizado de vírgulas relacionado a práticas de leitura e escrita.

Neste artigo, buscamos abordar os usos e não usos da vírgula em esquema duplo como objeto linguístico de investigação. Ao identificarmos usos e não usos da vírgula, classificamos os tipos de usos de vírgula que atendem ou não à convenção gramatical em usos convencionais e não convencionais, conhecidos, respectivamente, como "acerto" e "erro", do ponto de vista normativo.

\section{Material e Metodologia}

Os textos a serem analisados foram selecionados do Banco de Dados de Produções Escritas do EF II, desenvolvido a partir do projeto de extensão universitária da Universidade Estadual Paulista "Júlio de Mesquita Filho" (UNESP) - "Desenvolvimento de Oficinas pedagógicas de leitura, interpretação e produção textual no Ensino Fundamental". Esse projeto de extensão foi credenciado e financiado pela Pró-Reitoria de extensão (PROEx) da UNESP e efetivado no período de 2008 a 2011, em uma escola estadual, localizada no município de São José do Rio Preto. O projeto de extensão foi coordenado pelas professoras Dras. Luciani Ester Tenani e Sanderleia Longhin-Thomazi. Dentre outros resultados, esse projeto possibilitou a construção da plataforma on-line do Banco de Dados, disponível gratuitamente em: http://www.gdb.ibilce.unesp.br/redacoes, por meio 
de auxílio financeiro da FAPESP (Processo 2013/14.546-5). Ao todo, o banco de dados é formado por 5.519 textos produzidos por 622 alunos, organizados de modo a constituir uma amostra transversal e outra longitudinal.

Tendo em vista o propósito majoritário de atender, por meio das propostas, a comunidade externa e, como consequência, contribuir com a comunidade acadêmica, o projeto de extensão se desdobrou por duas vias fundamentais; na primeira, permitiram-se identificar os chamados problemas de uso da linguagem e, na segunda, os textos produzidos nas oficinas serviram para descrever processos que envolvem relações de fala e escrita, valorizando, assim, o letramento associado às práticas sociais. Dessa forma, são esses problemas de uso da linguagem pensados a partir da noção de letramento, em específico, do uso não convencional da vírgula, que nos permite analisar os dados de vírgula em esquema duplo sob um olhar que relaciona seu emprego com características da fala, deixando de lado, assim, a noção de erro. Essa proposta está em consonância com o projeto de extensão que originou o banco na medida em que, segundo Tenani e Longhin (2014, p. 21), o trabalho realizado na escola visou abordar "[...] temas como ortografia, pontuação, junção e textualidade, os minicursos, [...] visaram à melhoria do desempenho dos alunos do EFII na área de Português".

Vale destacar, ainda, que todas as atividades desenvolvidas pelo projeto pautaram-se na concepção de escrita como modo de enunciação (CORRÊA, 2004). Ademais, todas as propostas textuais, inicialmente desenvolvidas pelas docentes juntamente do auxílio de alunos voluntários/bolsistas do Projeto de Extensão - IBILCE/UNESP, foram elaboradas de acordo com a Proposta Curricular do Estado de São Paulo (2008), com base na tipologia textual prevista para cada ano letivo de acordo com esse documento.

Selecionamos do Banco de dados 38 textos para compor o material de análise deste artigo. Os textos foram escritos por alunos do $9^{\circ}$ ano do EFII a partir de proposta do gênero textual artigo de opinião. Tendo em vista o fato de haver mais de uma proposta para um mesmo gênero, optamos pela temática "Destruição do Planeta Terra" por ser a que teve maior número de textos produzidos. Nesse conjunto de 38 textos, encontramos 72 ocorrências de estruturas em que era passível o uso de vírgulas em esquema duplo e as classificamos por tipos e números de ocorrências. Dessa forma, foi possível identificar categorias de usos de vírgula em esquema duplo em que houve mais estruturas sintáticas em que vírgulas em esquema duplo seriam mobilizadas.

No que se refere à análise dos dados encontrados, foram estabelecidas quatro categorias possíveis para o emprego de vírgulas em esquema duplo, a saber: (i) presença-presença (11), quando se tem o emprego da vírgula nas duas posições previstas pela convenção; (ii) presença-ausência (1-0), quando se tem o emprego da vírgula apenas na primeira posição; (iii) ausência-presença (0-1), quando se tem o emprego da vírgula apenas na segunda posição; (iv) ausência-ausência (0-0), quando não se tem o emprego das duas vírgulas previstas pela convenção. 
As ocorrências (03), (04), (05) e (06), a seguir, exemplificam, respectivamente, as categorias de uso (i), (ii), (iii) e (iv) adotadas neste artigo.

(03) encontramos o nosso professor, que estava de férias com sua família, (Z08_8A_11M_06).

(04) de Sírio Possenti, professor de Linguística da Unicamp "uma coisa é" (Z08_8A_11M_04).

(05) estávamos no aeroporto nos preparando para a viagem que mudaria as nossas vidas, (Z08_8A_11M_06).

(06) não lembrou e no dia seguinte nem se desculpou (Z08_8A_11M_01).

Temos por objetivo, então, identificar e caracterizar usos e não usos de vírgula em esquema duplo, desde uma perspectiva descritiva, considerando a hipótese de que há uma relação entre o emprego da vírgula e as características da fala.

\section{Análise dos dados}

Nesta análise inicial dos dados, buscamos fazer um levantamento de todas as ocorrências de vírgula em esquema duplo encontradas nos textos, classificando-as por tipos de dados e número de ocorrências, a fim de encontrar regularidades quanto aos usos de vírgula em esquema duplo, além de comparar as ocorrências com outros dados de vírgula do $9^{\circ}$ ano do EFIl, analisados por Carvalho (2019). Na Tabela 1, distribuem-se as frequências de ocorrência dos dados convencionais e não convencionais de vírgula por ausência em esquema duplo.

Tabela 1. Usos de vírgulas e tipos de estruturas sintáticas

\begin{tabular}{c|c|c|c}
\hline & \multicolumn{2}{|c|}{ Tipos de estruturas } & Totais (\%) \\
\hline Usos de vírgulas & Deslocamento & Encaixamento & \\
\hline Convencional & $02(2,77 \%)$ & $05(6,94 \%)$ & $\mathbf{0 7}(\mathbf{9 , 7 1 \% )}$ \\
\hline Não convencional & $51(70,83 \%)$ & $14(19,44 \%)$ & $\mathbf{6 5}(\mathbf{9 0 , 2 7 \% )}$ \\
\hline TOTAIS & $\mathbf{5 3 ( 7 3 , 6 1 \% )}$ & $\mathbf{1 9 ( 2 6 , 3 8 \% )}$ & $\mathbf{7 2 ( 9 9 , 9 \% )}$ \\
\hline
\end{tabular}

Fonte: Elaboração própria

As frequências contidas na tabela mostram que os dados de vírgula em esquema duplo são mais recorrentes em estruturas sintáticas de deslocamento do que de encaixamento, no entanto, em ambos os contextos sintáticos prevalece o uso não convencional da vírgula. Em fronteira de deslocamento, as ocorrências representam $73,61 \%$ desse uso. Em fronteiras de encaixamento, as ocorrências representam 26,38\% desse uso. Dessa 
forma, em nenhuma das estruturas, seja de deslocamento ou encaixamento, os alunos tendem a empregar as vírgulas convencionalmente. Além disso, as frequências chamam atenção para o baixo emprego convencional da vírgula em esquema duplo.

Passamos a exemplificar o contexto sintático de deslocamento, o que mais ocorre no material analisado.

Figura 3. Exemplo de uso convencional da vírgula em esquema duplo em contexto sintático de deslocamento

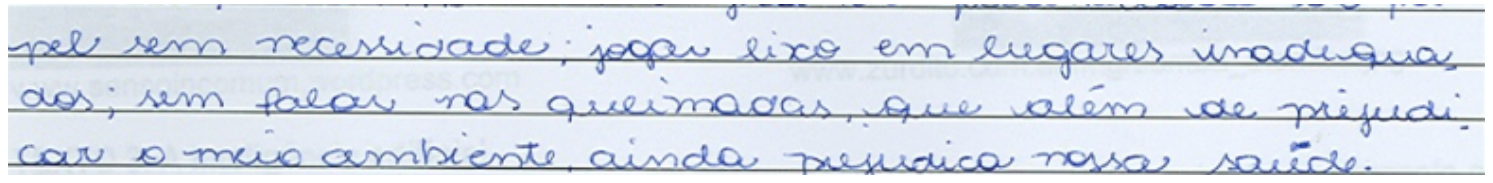

Texto: Z08_8C_11F_05

Figura 4. Exemplo de uso não-convencional da vírgula em esquema duplo em contexto sintático de deslocamento

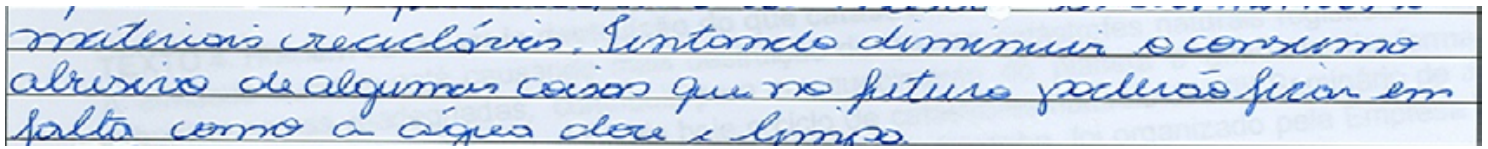

Texto: Z08_8C_02F_05

Já nos dados de encaixamento, a frequência do uso convencional de vírgula também é baixa se comparada ao não convencional, entretanto, esse é o contexto sintático que tem emprego convencional maior do que nas estruturas de deslocamento.

Figura 5. Exemplo de uso convencional de vírgula em esquema duplo em contexto sintático de encaixamento

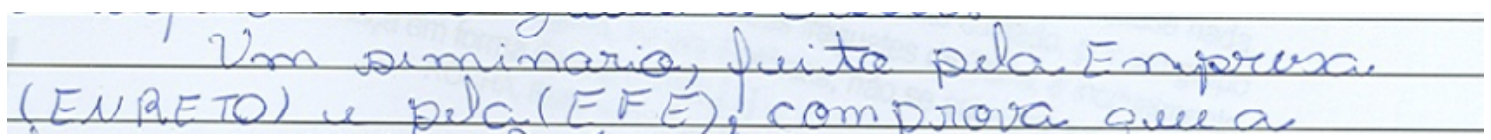

Texto: Z08_8C_15F_05

Figura 6. Exemplo de uso não convencional de vírgula em esquema duplo em contexto sintático de encaixamento

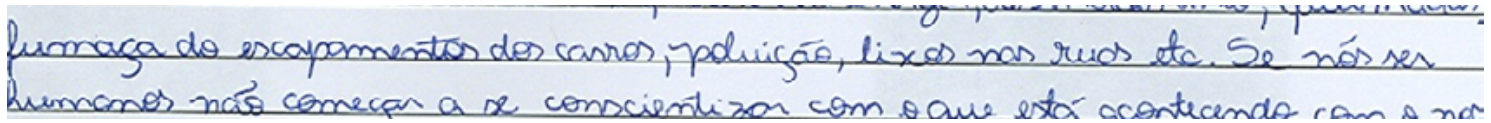

Texto: Z08_8C_22F_05 
Esses resultados já eram esperados, em certa medida, tendo por base Carvalho (2019), que analisou dados de vírgula em esquema simples. Segundo a autora, "[...] o uso da vírgula em fronteiras de deslocamento em esquema simples constitui igualmente contexto problemático na escrita de alunos do EFIl do ponto de vista sintático" (CARVALHO, 2019, p. 133). Dessa forma, seja em esquema duplo ou em esquema simples, os alunos tendem a não empregar vírgulas convencionalmente. Junto com Carvalho (2019, p. 133), podemos afirmar que: "[...] os alunos chegam ao final do EFIl sem ter adquirido regra sintática de uso da vírgula em fronteira de deslocamento".

Ainda Carvalho (2019), a partir de análise quantitativa das ocorrências em fronteiras de deslocamento e encaixamento, elaborou um gráfico (Gráfico 10. Médias dos usos de vírgulas convencionais e não convencionais em esquema duplo por ano letivo, p. 131) em que levantou duas regularidades em relação aos usos de vírgulas em esquema duplo e uma delas refere-se ao $9^{\circ}$ ano. Nesse caso, segundo a autora: "[...] no $9^{\circ}$ ano, as médias [média do emprego convencional $(0,034)$ e do emprego não convencional $(0,42)$ ] se distanciam entre si, sendo o uso não convencional muito superior em função do uso convencional" (CARVALHO, 2019, p. 132). Essa regularidade pode ser notada nas ocorrências analisadas nesta pesquisa, conforme mostra o Gráfico 1.

Gráfico 1. Vírgulas em fronteiras sintáticas do esquema duplo

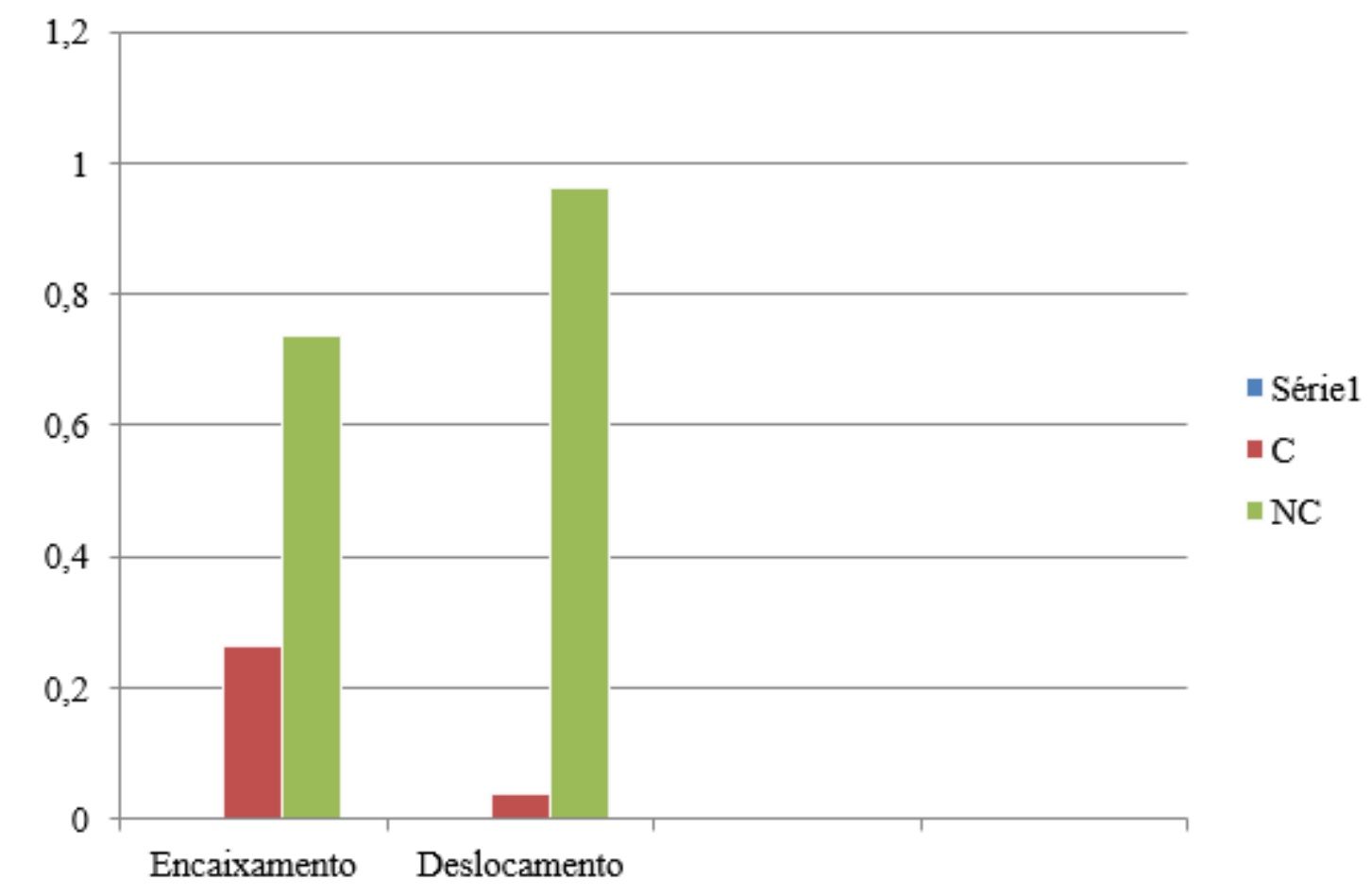

C: Uso convencional; NC: uso não convencional por ausência.

Fonte: Elaboração própria 
De um viés quantitativo, pode-se notar, no Gráfico 1, que o uso não convencional da vírgula se sobressai ao uso convencional, distanciando significativamente dos usos de vírgula em esquema duplo. Esse gráfico mostra tendência semelhante àquela apontada por Carvalho (2019, p. 132) de que as médias dos usos de vírgula em esquema duplo não se aproximam ao final do EFII e de que "[...] quando estruturas em esquema duplo emergem nos textos da amostra, suas fronteiras não são delimitadas convencionalmente pela vírgula, em especial, ao final do EFII".

Um dos fatores que pode contribuir para esse aumento de estruturas deslocadas e encaixadas nos anos finais é o gênero, nesse caso, o artigo de opinião. Dentre o conteúdo programático previsto para o $9^{\circ}$ ano do EFII, na Proposta Curricular do estado de São Paulo (2008), está a leitura e produção de texto de gêneros argumentativos juntamente do estudo da pontuação, do período composto por coordenação e por subordinação. Nos dados longitudinais, Carvalho (2019) afirma haver indícios de emergência de estruturas deslocadas como adjuntos adverbias ("um dia"), orações subordinadas adverbiais temporais ("quando vamos tomar banho") e subordinadas adverbiais condicionais ("se acordarmos agora"). Esse aumento de estruturas em esquema duplo no último ano do EFII não significa uso convencional dessas vírgulas, o que levou a autora a ponderar que "[...] há, portanto, certa complexidade envolvida no emprego da vírgula em esquema duplo, o que contribui para a conclusão de que a informação sintática não é suficiente para garantir que a vírgula, no contexto mencionado, seja utilizada de forma convencional" (CARVALHO, 2019, p. 138).

Tendo em vista essas considerações gerais, passamos a aprofundar, em relação ao estudo feito por Carvalho (2019), as ocorrências e ausências de vírgulas, tendo em conta as quatro possibilidades de utilização da vírgula em esquema duplo, a saber: (i) presença-presença: 1-1 (uso convencional); (ii) presença-ausência: 1-0; (iii) ausênciapresença: 0-1; (iv) ausência-ausência: 0-0 (usos não convencionais). Na Tabela 2, abaixo, apresentamos as frequências de usos de vírgulas, em função dos dois tipos de estruturas consideradas: deslocamento e encaixamento.

Tabela 2. Tipologia de uso da vírgula em esquema duplo

\begin{tabular}{c|c|c|c}
\hline & \multicolumn{2}{|c|}{ Tipo de estrutura } & \\
\hline Tipo de Usos & Deslocamento & Encaixamento & TOTAL $(\%)$ \\
\hline Presença-Presença (1-1) & $02(2,77 \%)$ & $05(6,94 \%)$ & $\mathbf{0 7}(\mathbf{9 , 7 1 \% )}$ \\
\hline Ausência-Ausência (0-0) & $38(52,77 \%)$ & $05(6,94 \%)$ & $\mathbf{4 3 ( 5 9 , 7 \% )}$ \\
\hline Ausência-Presença (0-1) & $04(5,55 \%)$ & $06(8,33 \%)$ & $\mathbf{1 0 ( 1 3 , 8 8 \% )}$ \\
\hline Presença-Ausência (1-0) & $09(12,5 \%)$ & $03(4,16 \%)$ & $\mathbf{1 2 ( 1 6 , 6 6 \% )}$ \\
\hline TOTAL & $\mathbf{5 3 ( 7 3 , 6 1 \% )}$ & $\mathbf{1 9 ( 2 6 , 3 8 \% )}$ & $\mathbf{7 2 ( 9 9 , 9 \% )}$ \\
\hline
\end{tabular}

Fonte: Elaboração própria 
A partir dos dados dispostos na tabela, nota-se que em fronteiras de deslocamento, em $73,61 \%$ dos dados, é tendência que nenhuma das fronteiras do enunciado seja segmentada com a vírgula (0-0). E em fronteiras de encaixamento, em $26,38 \%$ dos dados, nenhuma das fronteiras do enunciado é segmentada com a vírgula (0-0).

Passamos a exemplificar o tipo de estrutura distribuído no tipo de usos da vírgula em esquema duplo.

Figura 7. Exemplo de uso convencional de vírgula em esquema duplo em contexto sintático de deslocamento por presença-presença (1-1)

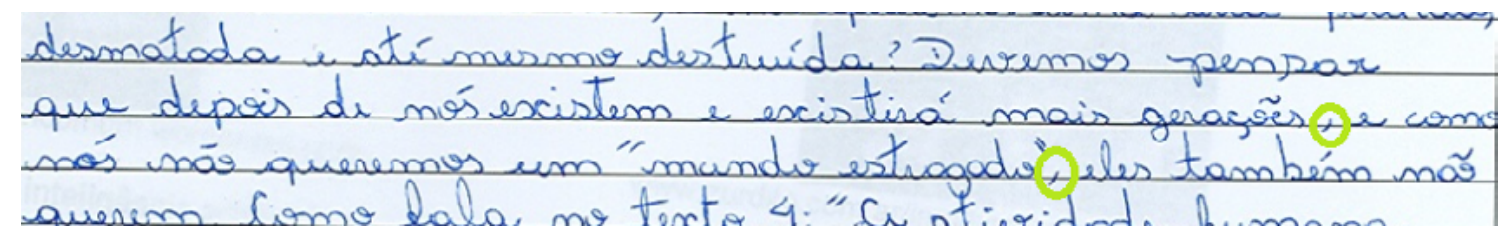

Texto: Z08_8C_18F_05

Figura 8. Exemplo de uso não convencional de vírgula em esquema duplo em contexto sintático de deslocamento por ausência-ausência (0-0)

(1) ypoder destrutivo do honem, estó pouce a pares $\theta-$

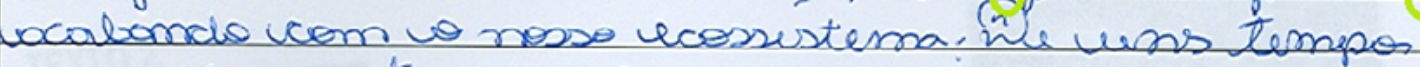

Texto: Z08_8C_02F_05

Figura 9. Exemplo de uso não convencional de vírgula em esquema duplo em contexto sintático de deslocamento por ausência-presença (0-1)

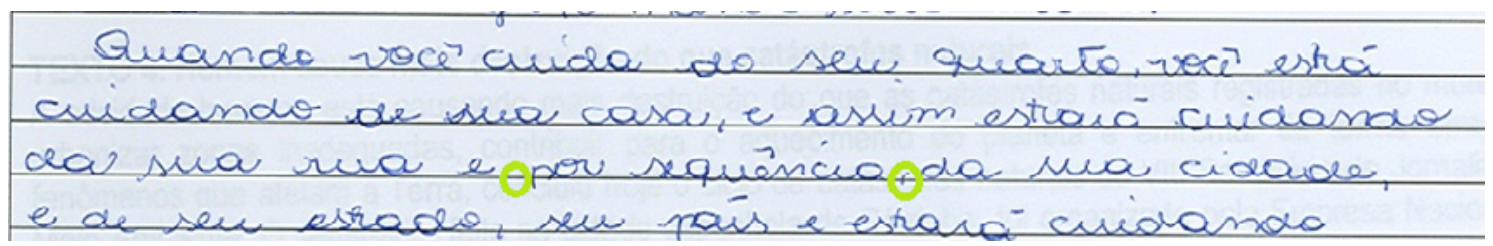

Texto: Z08_8C_11F_05

Figura 10. Exemplo de uso não convencional de vírgula em esquema duplo em contexto sintático de deslocamento por presença-ausência (1-0)

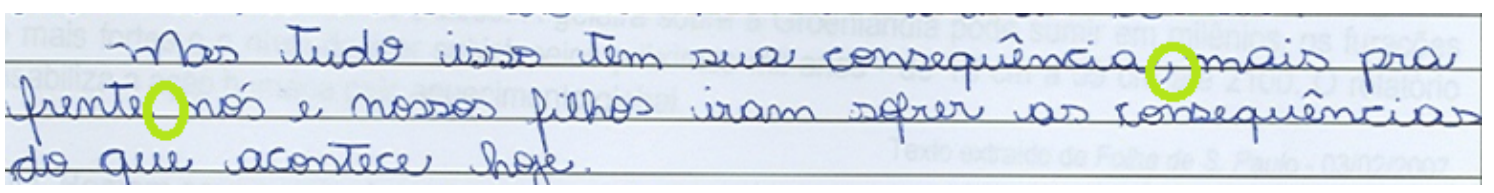

Texto: Z08_8C_09F_05 
Figura 11. Exemplo de uso convencional de vírgula em esquema duplo em contexto sintático de encaixamento por presença-presença (1-1)

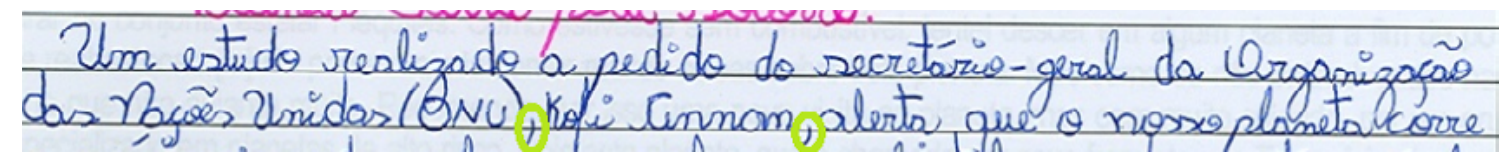

Texto: Z08_8C_34F_05

Figura 12. Exemplo não convencional de vírgula em esquema duplo em contexto sintático de encaixamento por ausência-ausência (0-0)

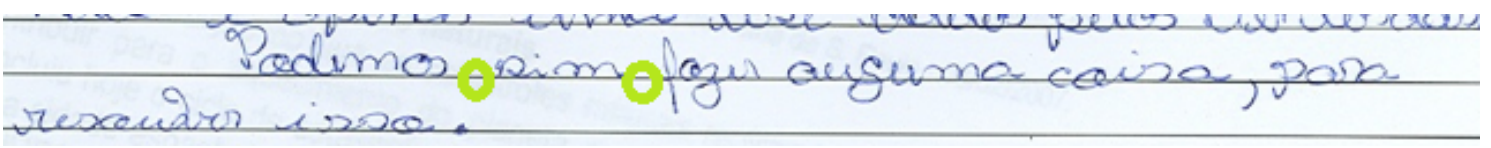

Texto: Z08_8C_15F_05

Figura 13. Exemplo não convencional de vírgula em esquema duplo em contexto sintático de encaixamento por ausência-presença (0-1)

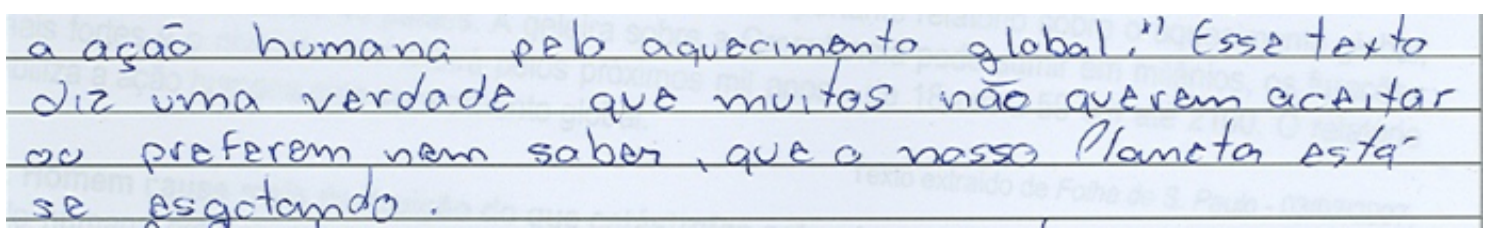

Texto: Z08_8A_16M_05

Figura 14. Exemplo não convencional de vírgula em esquema duplo em contexto sintático de encaixamento por presença-ausência (1-0)

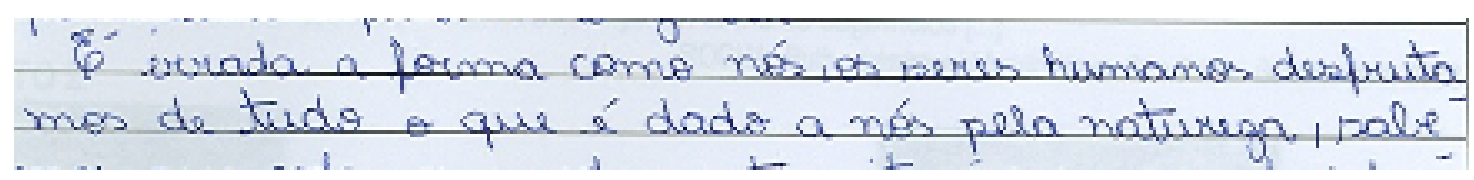

Texto: Z08_8A_17F_05

A partir da análise dos dados, podemos observar que, em relação ao emprego de vírgulas em esquema duplo, há dois contextos sintáticos possíveis para o emprego da vírgula nas duas fronteiras do enunciado: deslocamento e encaixamento. No que concerne a esses contextos, a estrutura sintática mais mobilizada é a de deslocamento. Entretanto, em ambos os contextos o que prevalece é o uso não convencional da vírgula em esquema duplo, ou seja, no $9^{\circ}$ ano do EFIl os alunos tendem a empregar mais vírgulas em esquema duplo, no entanto, tal fato não significa o uso convencional da vírgula, pelo contrário. Além disso, notamos também que nesse uso não convencional o que prevalece é o não uso em nenhuma das duas fronteiras previstas do enunciado (Ausência-Ausência). Dessa forma, esses resultados corroboram a pesquisa de Carvalho (2019), na medida em que se aproximam e apontam regularidades quanto ao uso e não uso da vírgula em esquema duplo. 


\section{Considerações finais}

Este artigo teve como objetivo central identificar e caracterizar os usos e não usos de vírgula em esquema duplo em textos do último ano do EFII. Consideramos como ponto de partida a assunção de que o emprego de vírgula está relacionado a características da fala, a partir da noção de heterogeneidade da escrita, defendida por Corrêa (2004). Buscamos evidenciar como essa noção se faz notória nos usos e não usos da vírgula em textos escolares, tendo em vista que esses usos e não usos relatam a circulação do escrevente, nesse caso, do aluno, pelas práticas orais/faladas e letradas/escritas.

Ademais, também procuramos partir da noção da multidimensionalidade da pontuação, como defende Chacon (1998), e no que se refere às dimensões envolvidas, privilegiamos a dimensão sintática nesse momento da análise.

Levando em consideração que no $9^{\circ}$ ano do EFII um dos conteúdos de ensino previstos são as regras sintáticas para o uso da pontuação juntamente do ensino de estruturas coordenadas e subordinadas, pudemos observar, a partir dos dados, que, nesse ano letivo, o aluno flutua entre o uso e não uso da vírgula em esquema duplo, prevalecendo o não uso. É justamente essa flutuação que nos mostra o encontro entre as práticas do oral e do escrito e, principalmente, a tentativa de os alunos se adequarem a um código de escrita institucionalizado que é privilegiado nas escolas até hoje, a partir do ponto de vista normativo. Dessa forma, buscamos demonstrar que, do nosso ponto de vista, é necessário um ensino da escrita pautado na noção de escrita como modo de enunciação, para que possamos ver o sujeito da linguagem, o aluno, aparecer no seu discurso escrito, valorizando, assim, seu já contato com práticas orais/letradas.

\section{REFERÊNCIAS}

ARAÚJO-CHIUCHI, A. C. Os usos não-convencionais da vírgula em textos de alunos da quinta série do Ensino Fundamental. 2012. Dissertação (Mestrado em Teoria e Análise Linguística) - Instituto de Biociências, Letras e Ciências Exatas, Universidade Estadual Paulista "Júlio de Mesquita Filho", São José do Rio Preto, 2012.

BRASIL. Base Nacional Comum Curricular (BNCC). Educação é a Base. Brasília, MEC/ CONSED/UNDIME, 2017. Disponível em: http://basenacionalcomum.mec.gov.br/ images/BNCC_EI_EF_110518_versaofinal_site.pdf. Acesso em: 15 mar. 2019.

CARVALHO, T. G. Usos de vírgulas em textos do Ensino Fundamental II: um estudo longitudinal. 2019. Dissertação (Mestrado em Análise Linguística) - Instituto de Biociências, Letras e Ciências Exatas. Universidade Estadual Paulista "Júlio de Mesquita Filho", São José do Rio Preto, 2019.

CHACON, L. Oralidade e Letramento na construção da pontuação. Revista Letras, Curitiba: Editora UFPR, n. 61, especial, p. 97-122, 2003. 
CHACON, L. Ritmo da escrita: uma organização do heterogêneo da linguagem. São Paulo: Martins Fontes, 1998.

CORRÊA, M. L. G. O modo heterogêneo de constituição da escrita. São Paulo: Martins Fontes, 2004.

CORRÊA, M. L. G. Letramento e heterogeneidade da escrita no ensino de Português. In: SIGNORINI, I. (org.). Investigando a relação oral/escrito e as teorias de letramento. Campinas: Mercado de Letras, 2001. p. 135-166.

DAHLET, V. As (man)obras da pontuação: usos e significações. São Paulo: Associação Editorial Humanitas, 2006.

PROPOSTA CURRICULAR DO ESTADO DE SÃO PAULO: Língua Portuguesa - ciclo II. Coord. Maria Inês Fini. São Paulo: Secretaria Estadual da Educação, 2008. Disponível em: www.rededosaber.sp.gov.br/portais/Portals/19/arquivos/Prop_LP_COMP_red_ md_20_03.pdf. Acesso em: 12 mar. 2019.

SONCIN, G. C. N. Língua, discurso e prosódia: investigar o uso da vírgula é restrito? Vírgula! 2014. Tese (Doutorado em Análise Linguística) - Instituto de Biociências, Letras e Ciências Exatas, Universidade Estadual Paulista "Júlio de Mesquita Filho", São José do Rio Preto, 2014.

SONCIN, G.; TENANI, L. Emprego de vírgula e prosódia do Português Brasileiro: aspectos teórico-analíticos e implicações didáticas. Filol. Linguíst. Port., São Paulo, v. 17, n. 2, p. 473-493, jul./dez. 2015.

SONCIN, G.; RODRIGUES, A. de A. A interação sintaxe-prosódia em usos de vírgula em esquema duplo: apontamentos para o ensino da pontuação.DOMÍNIOS DE LINGU@GEM, v. 12, p. 1571-1606, 2018.

TENANI, L. E.; LONGHIN THOMAZI, S. R. Oficinas de leitura, interpretação e produção textual no ensino fundamental. Revista em Extensão (on-line), v. 13, p. 20-34, 2014. Disponível em: www.seer.ufu.br/index.php/revextensao/article/viewFile/27049/14678. Acesso em: 26 ago. 2019.

TENANI, L. E.; LONGHIN THOMAZI, S. R. Banco de Dados de Escrita do Ensino Fundamental II. Disponível em: http://www.convenios.grupogbd.com/redacoes/Login. Acesso em: 08 ago. 2019. 